\title{
Recent Changes in Braided Planform of the Tista River in the Eastern Lobe of the Tista Megafan, India
}

\author{
Raghunath Pal and Padmini Pani \\ Centre for the Study of Regional Development, School of Social Science, \\ Jawaharlal Nehru University, New Delhi-110067, India \\ Email: raghunath.geo17@gmail.com
}

\begin{abstract}
The study has taken the opportunity of Landsat (1990-2010) satellite images, SRTM digital elevation model data and water discharge data of one gauging station to understand the temporal dynamics of the Tista River in the last two decades. Along with the enormous impact of flash floods the construction of Gajoldoba Barrage has played the key to change the braided planform of the river. The river upstream of Gajoldoba Barrage is characterized by eastward shifting (upper portion), westward shifting (an immediate upper portion of the barrage), decreasing sinuosity, increasing braid-channel ratio, an increase in the number of sub-channels and a reduction in the size of channel bars etc. The river downstream of the barrage is characterized by westward migration, decreasing sinuosity, increasing braid-channel ratio, an increase in the number of subchannels, and a reduction in the size of channel bars etc. moreover, the study reflects a significant comparison of the morphological dynamics between the up and downstream of the river.
\end{abstract}

Keywords: Tista River, Braid-channel ratio, Sinuosity index, flash flood, Gajoldoba Barrage, Discharge, Satellite images

\section{Introduction}

The establishment and growth of theoretical framework of the classification of riverform started about 70 years ago through the publication of two landmark research works, i.e., the work of Lane (1957) as well as that of Leopold and Wolman (1957). Since the publications, the concept of meandering-braiding threshold has remained as one of the key methods of channelform classification (Eatonet al., 2010). The idea contains a threshold discharge-slope relationship that was criticized by many scholars later. In order to discriminate the meandering and braiding of a channel,Henderson (1966) proposed the concept of critical slope for coarse bed material transport (Carson, 1984). In 1981 Begin offered a physical basis for the explanation of braiding complexities that contains the value of average shear stress (the average shear stress stands for the specific weight of channel fluid and the downstream hydraulic geometry coefficient) (Carson, 1984). Other ways to identify a channel whether it is meandered or braided are based on the analysis of braid-channel ratio and sinuosity index. There is a universal reversal relationship between braid-channel ratio and sinuosity index that has also been found in many north Indian rivers especially the river systems of the Himalayan foreland (Kosi, Gandak, Baghmati, Burhi Gandak and KamalaBalan etc.) (Sinha and Friend, 1994). 
The Tista River, however, has some similar geomorphic characteristics with that of the Kosi River as both are the river of the foreland Himalaya and have formed foothill megafans. The Tista River meanders and single thread in its mountain course. The river is highly braided from where it is emerging onto the Gangetic and Brahmaputra Plains because of the huge reduction of slope and the bank impediments. The construction of Gajoldoba Barrage, however, has a considerable role in the downstream braiding and the flow pattern of the river. Furthermore, the Tista Basin is highly sensitive in terms of its highest sediment yield (98.40 cum/ha/yr.) among all the Himalayan rivers and the occurrences of landslides and flash floods (Agarwal and Narain, 1991).Flash floods are the common phenomenon in this basin that extensively influenced the formation of the Tista Megafan as well as the channel structure. The braided structure of the river has formed from the immediate foreland of the Himalaya. Hence, the study reach of the river is highly affected by flash flood events. Furthermore, the river is highly controversial in the context of geopolitics notably the water distribution issue between India and Bangladesh (Rudra, 2010).

However, the present study is intended to have an understanding of the temporal dynamics of braidness and the changes in the flow pattern and direction at different reaches in the braided trough of the channel.

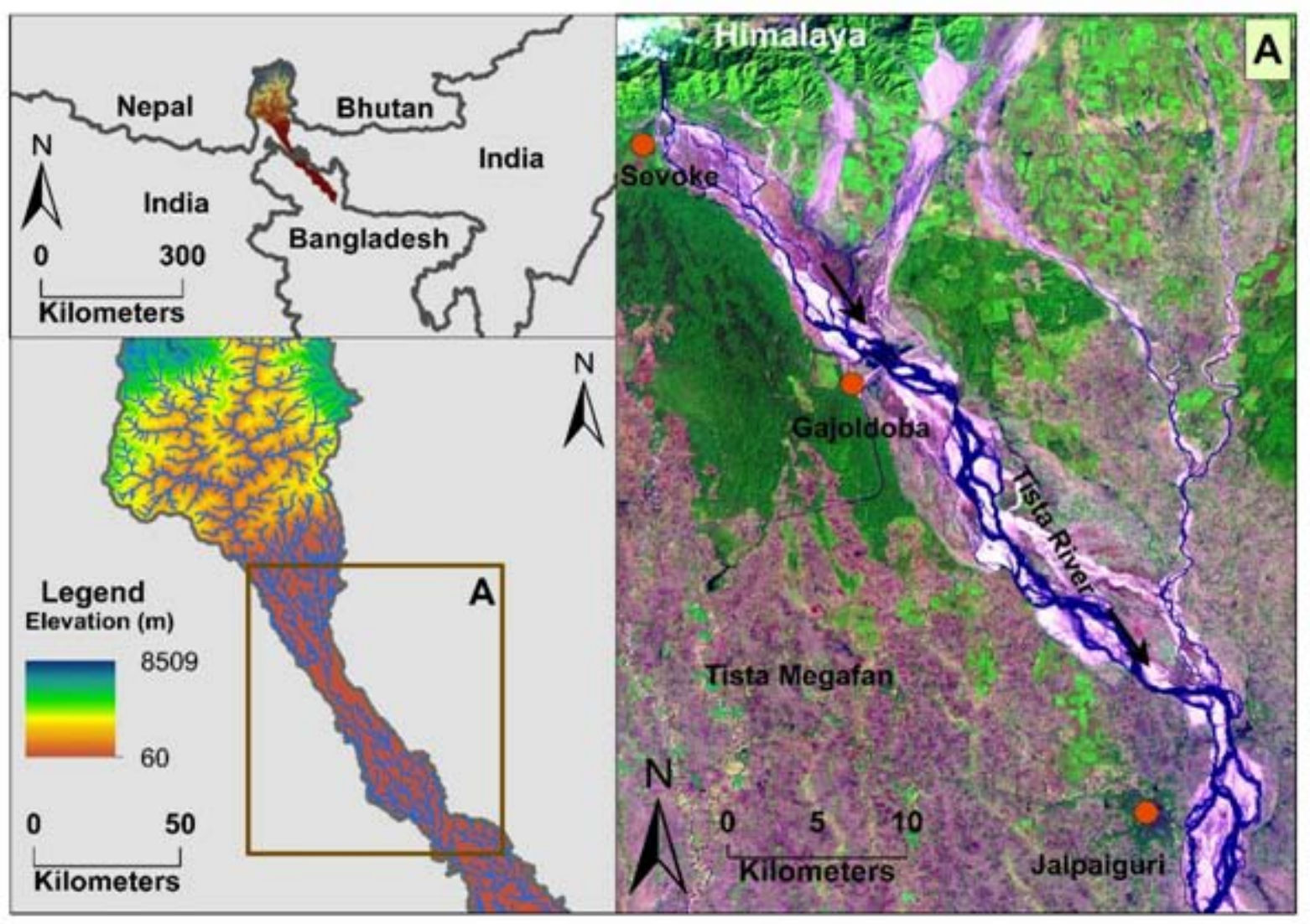

Fig.1: The map of the study reach of the Tista River. 'A' indicates the study portion of the river. 


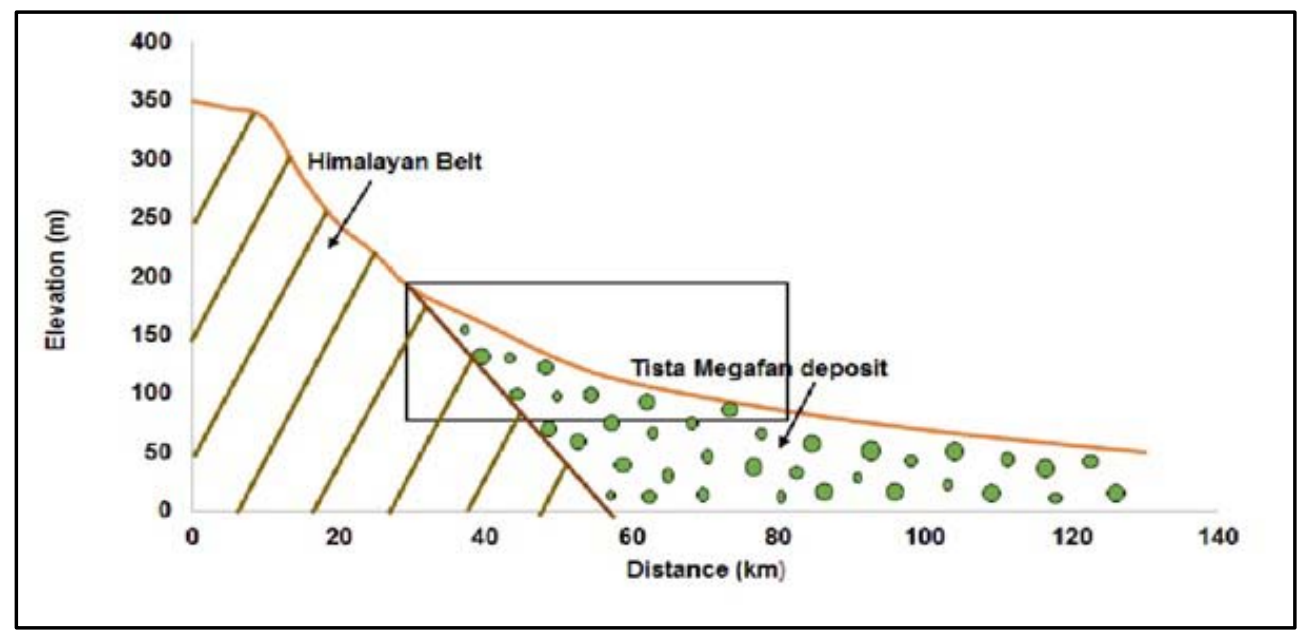

Fig.2:The longitudinal profile of a stretch of the Tista River. The box exhibits the longitudinal profile of the study reach. The study portion of the river is located in the foothill and the Tista Megafan belt.

\section{Description of the Study Reach}

The Tista River is a major tributary of the Brahmaputrariver as well as a transboundary river that crosses the Indo-Bangladesh boarder. The total basin area is about 12160 $\mathrm{km}^{2}$ in Sikkim, West Bengal and Bangladesh (Mukhopadhyay, 1982). The river has its origin in the Sikkim Himalaya. It is one of the fiercest rivers among all the Himalayan Rivers. The river drains about $105 \mathrm{~km}$ through the Sikkim and Darjeeling Hills. The river then enters the north-eastern portion of large Ganga-Brahmaputra Plain (Wadia, 1975; Singh, 1971; Mukhopadhyay, 1982; Ghosh, 2013). The river flows to the south and finally confluxes to the Brahmaputra River in Bangladesh (Fig. 1). The river has formed a large fan (called Tista Megafan) ( 18000 $\left.\mathrm{km}^{2}\right)$ in the foothill and Gangetic Plain region and the river is flowing through to the eastern portion of the Megafan (Chakraborty and Ghosh, 2010). The trough of the river in the plain and the Megafan area had changed massively during the early sixteenth century and after that the river has been changed by flash floods and continuous sediment deposition The river was a tributary of the Ganga up to the end of the $18^{\text {th }}$ century but after the destructive flood of 1787, the channel had shifted eastwards and met the Brahmaputra (Agarwal and Narain, 1991). The longitudinal profile of the river indicates that the river trough is gently sloppy to the south in the Gangetic-Brahmaputra Plain (Fig. 2). The study reach of the river is about $50 \mathrm{~km}$ long from Sevoke to Jalpaiguri. The entire reach is in India and is highly braided. The study reach has been divided into two parts, i.e., upstream of Gajoldoba Barrage and downstream of the Gajoldoba Barrage for a detailed investigation.

\section{Data Used and Methods}

In this study, satellite remote sensing data of Landsat TM sensor (ground resolution $30 \mathrm{~m}$ ) of 1990 and 2010 were used. The study reach of the river is dynamic because of its geomorphological setting, fragile geology and the construction of Gajoldoba Barrage. The barrage has a significant role in the recent planform dynamics of the river especially in the upstream and downstream of the barrage. Hence, the last 20 years (1990-2010) was taken for the study and Landsat TM data of 1990 and 2010 were used because the barrage was 
commenced in 1993. In order to analyse the braided dynamics the study reach has been divided into upstream and downstream reaches. The upstream reach includes the river stretch from Sevoke to Gajoldoba Barrage whereas the river stretch from Gajoldoba Barrage to Jalpaiguri was considered as the downstream reach. SRTM digital elevation data were used for the construction of the longitudinal profile (Fig. 2). The validation of SRTM data was done some spot heights had been taken from the topographic sheets $(1: 250,000)$ of 1955 and the validation result was acceptable $\left(\mathrm{R}^{2}=0.950\right)$. The Google Earth images had been used in this study for a detail depiction of the braided form of the river. Furthermore, it also helped for some geomorphic measurements and to get a detailed account of the study reach.

For a detailed analysis of the changing braided form of the study reach two channel geometric parameters had been taken viz. braid-channel ratio (Friend and Sinha, 1993) and sinuosity index. The construction of Gajoldoba Barrage has a significant role in the discharge variability that enforces the dynamic processes of braiding, meandering and other geometric characteristics (i.e., cross-sectional changes, stream gradient changes etc.) of the channel. The barrage is located at the mid length of study reach, hence, a series of mean annual discharge data of 1995-2010 of Gajoldoba Barrage had been used in this study. A stage-discharge relationship has been prepared with the help of the stage-discharge data of Gajoldoba barrage for further analysis (Sefe, 1996; Subramanya, 2013).

Table-1: A brief account of the used data in the study.

\begin{tabular}{lll}
\hline Data Types & Description & Sources \\
\hline Topographic Sheets & $1955(1: 250,000)$ & $\begin{array}{l}\text { University of Texas } \\
\text { Library }\end{array}$ \\
$\begin{array}{l}\text { Satellite Images } \\
\text { Landsat TM }\end{array}$ & $\begin{array}{l}\text { 1990, 2010 (February) } \\
\text { (30 m ground resolution) }\end{array}$ & USGS Earth Explorer \\
$\begin{array}{ll}\text { Elevation Data } \\
\text { SRTM Void filled }\end{array}$ & $\begin{array}{l}2000 \text { (90 m ground } \\
\text { resolution) }\end{array}$ & USGS Earth Explorer \\
$\begin{array}{l}2015 \\
\text { Google Earth Images }\end{array}$ & $\begin{array}{l}\text { Gog3-2010 of Gajoldoba } \\
\text { Barrage }\end{array}$ & $\begin{array}{l}\text { Irrigation and Waterways } \\
\text { Department, West Bengal } \\
\text { Govt. }\end{array}$ \\
\hline
\end{tabular}

\section{Explanation}

\section{Braiding in the upstream of the barrage:}

A comparison between 1990 and 2010 maps displays the changing braided pattern of the Tista River in the upstream of Gajoldoba Barrage (Fig. 3). The alphabets and plus signs indicate the lateral shifting of sub-channels with respect to the marked points (Fig. 3). Figure 3 displays that two eastern sub-channels have completely disappearedon the 2010 map at ' $a$ ' and 'd' points. The number of sub-channels has increased in 2010 that leads to an increase in the number of channel bars. The size of the channel bars however, has decreased as the result of the increasing rate of channel bifurcation. The aerial span of the braided form has also decreased across the channel in the 2010 map. These all are probably because of the construction of Gajoldoba Barrage that leads to the reduction of flow velocity, channel bed slope and high channel bed sedimentation etc. A new large bar that has formed just above the barrage, is an indicator of high sedimentation after the barrage construction period (Fig. 3). 
The changes mainly occurred towards the left bank floodplain and channel bed of the river whereas the right bank of the river remains almost stable. It is because of the existence of a large forest belt on the right bank floodplain. Further, there is a clear-cut disappearance of the sub-channels in the upper portion (east) of the upstream whereas a number of new subchannels have formed in the lower portion (west) of the upstream of the barrage.

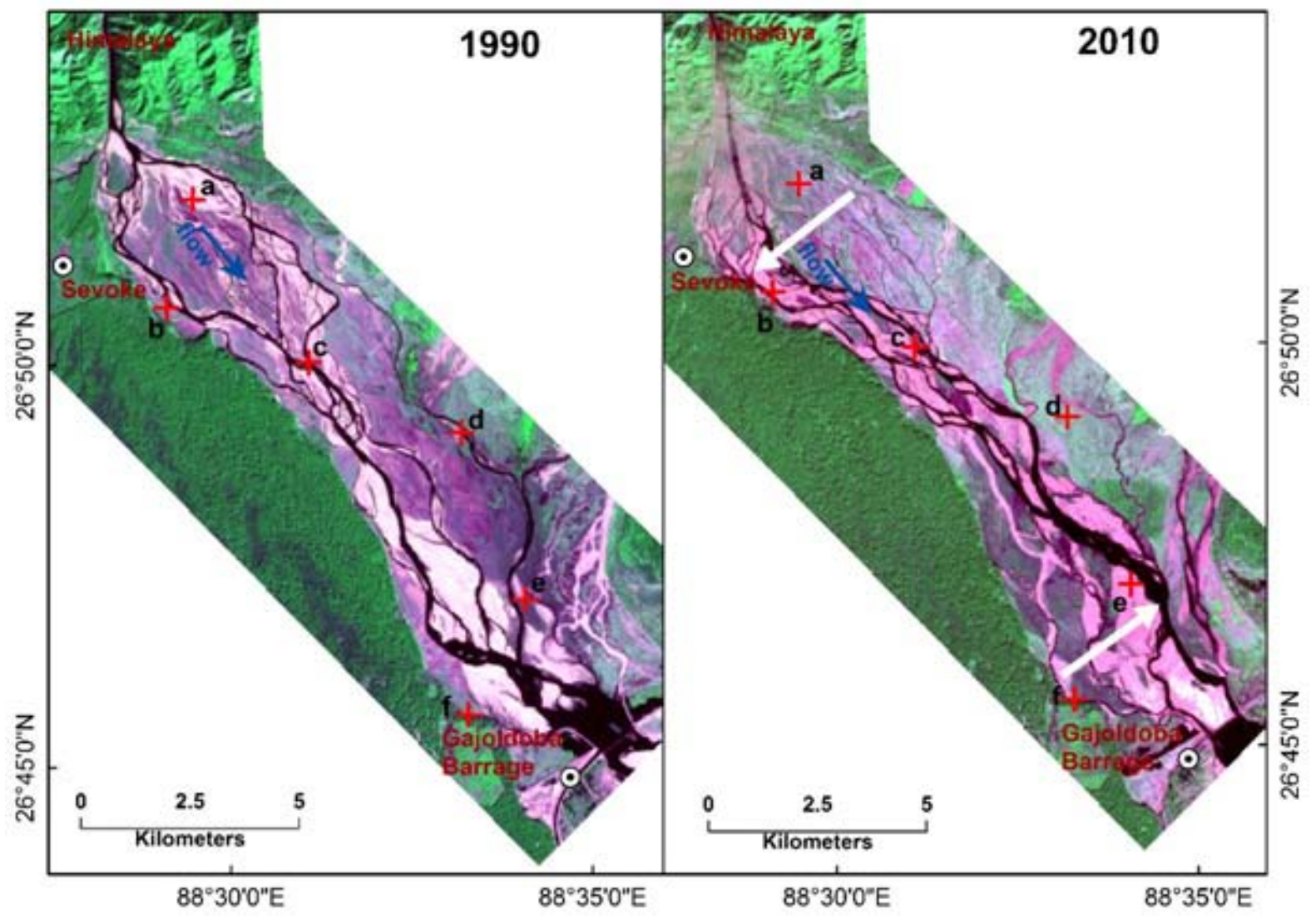

Fig. 3:Changing braided planform of the Tista River in the upstream of Gajoldoba Barrage between 1990 and 2010. The alphabets (a-f) and black colour plus signs display the relative position of the sub flows in the period of 1990-2010.

Other important features regarding the changing braided form in the upstream of the barrage are the changes in braid-channel ratio and sinuosity index. There is a sharp reduction of sinuosity of the channel from 1.16 to 1.08 in the period of 1990-2010 but the braid channel ratio has increased from 3.8 to 4.3 in the same period (Fig. 5-a). The results of braid-channel ratio and sinuosity reflect the reversal eternity of these two geometric parameters(Friend and Sinha, 1993). Another significant aspect is the trend of shifting the main flow. There is a sharp westward movement of the channel in the foothill area (just below the Himalaya) whereas the channel is shifted to eastward just above the barrage (Fig. 3).

\section{Braiding in the downstream of the barrage}

The comparison between 1990 and 2010 maps exhibits the braided planform changes of the Tista River in the downstream of Gajoldoba Barrage. Figure 4 displays the channel is highly curved and stable at two places viz.Immediately downstream of the barrage and near Jalpaiguri. The number of sub-channels has also increased in the downstream of the barrage along with the number of bars. As a result size of the bars has reduced. The aerial span of the braided form has also reduced across the channel on the 2010 map with respect to 
the 1990 map. A bar exists in the immediate downstreamon the 1990 map of the barrage but it is completely disappeared in the 2010 map (Fig. 4). It is probably because of the high flow velocity in the immediate downstream during the release of water from the barrage. Further, two sub-channels near ' $\mathrm{i}$ ' and ' $\mathrm{m}$ ' are invisible on the 2010 map and both exist on the 1990 map.

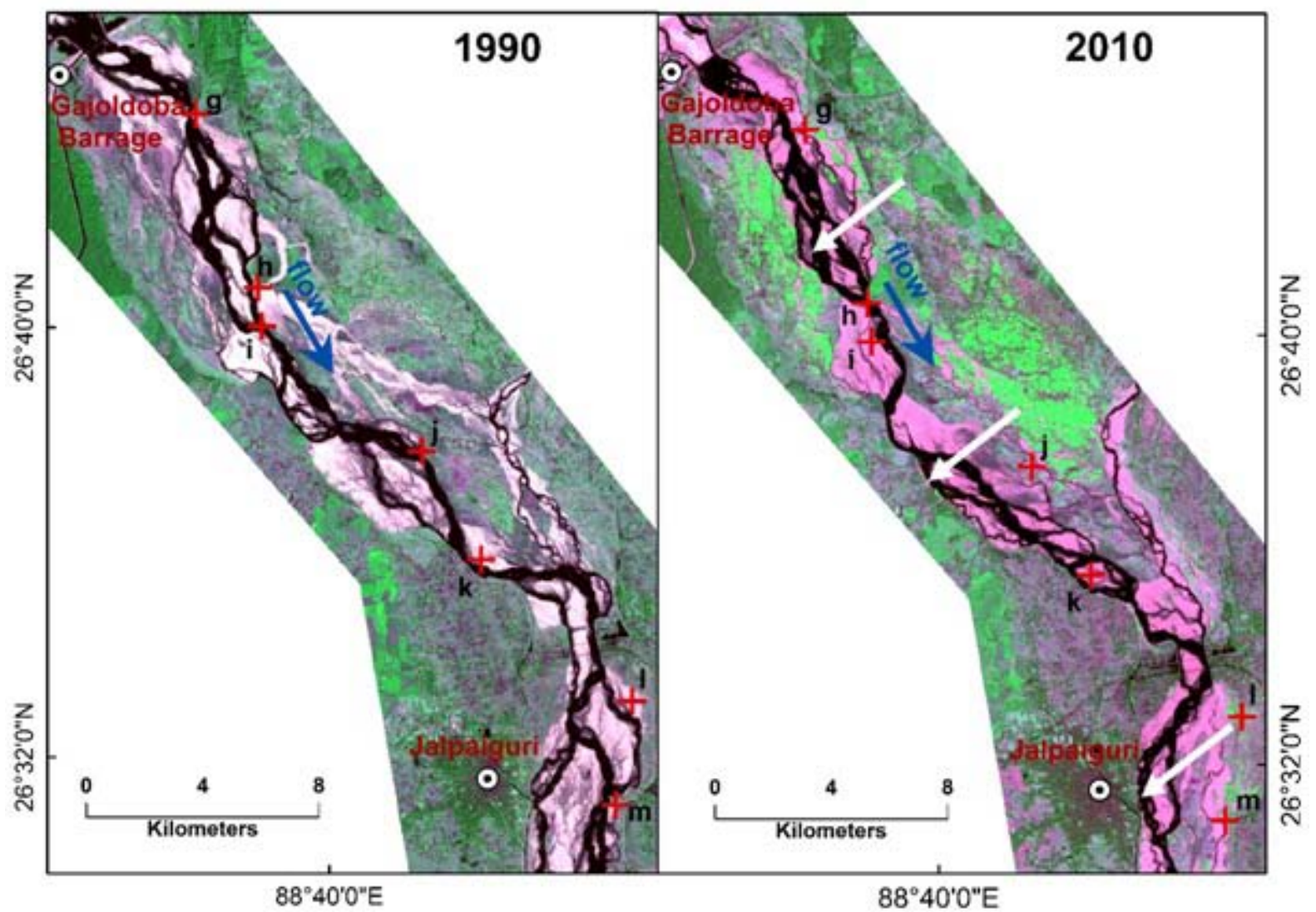

Fig. 4:Changing braided planform of the Tista River in the downstream of Gajoldoba Barrage between 1990 and 2010. The alphabets (g-m) and black colour plus signs display the relative position of the sub flows in the period of 1990-2010.

The important features related to the changing braided form in the upstream of the barrage are also the changes in braid-channel ratio and sinuosity index for the downstream of the barrage. There is a sharp reduction of sinuosity of the channel from 1.15 to 1.07 in the period of 1990-2010 but the braid channel ratio has increased from 3.6 to 2.9 in the same period (Fig. 5-b). The results of braid-channel ratio and sinuosity again reflect the reversal eternity of these two geometric parameters(Friend and Sinha, 1993). The sinuosity and braidchannel ratio both are relatively higher in the upstream than the downstream of the barrage. Another notable aspect is the trend of shifting the main flow. The comparison between 1990 and 2010 map sharply indicates that the entire reach has moved towards the west in the downstream of the barrage (Fig. 4). All the alphabets and red colour plus signs show the relative eastward shifting of the channel (g-m). Probably, the barrage has a significant impact on the westward movement of the channel in terms of the changing discharge flow and the channel bed sedimentation. 


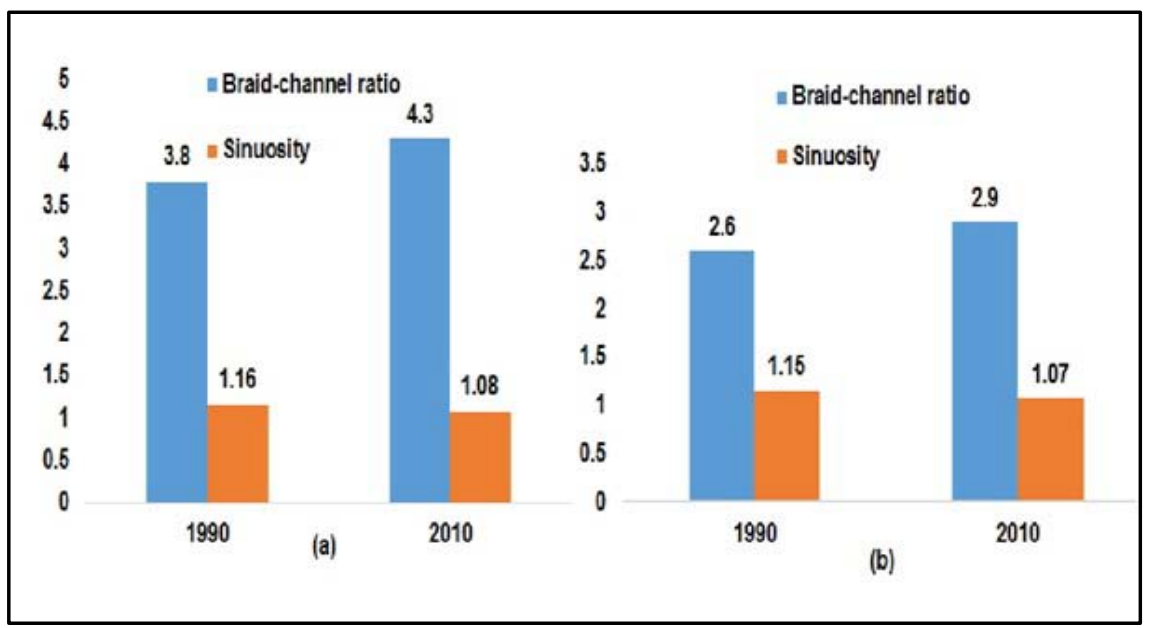

Fig. 5: Variability of braid-channel ratio and sinuosity in the upstream (a) and downstream (b) in the period of 1990-2010.

\section{Discussion}

The study explores the dynamic braided character of the Tista River from Sevoke to Jalpaiguri. The recent changes indicate that the barrage has played a very significant role in the braided form of both up and downstream of the barrage. The sinuosity of the entire study reach is almost same but braid channel ratio is very high in the upstream relative to the downstream in 1990 and 2010. The river flows the eastern boundary of the Tista Megafan and a number of tributaries are flowing in the south-west direction and meet the Tista in the left floodplain. But there is no such tributaries from the right side and the existence of a large forest belt continue the stability of the right bank of the river in the proximal part of the Tista Megafan (the eastern lobe). Furthermore, temporal variability of discharge has a very crucial role in the dynamics of the river as the river floor is highly controlled by a flash flood. Figure 6 shows the daily average discharge variability at Gajoldoba Barrage in the period of 19952010 that reflects the discharge behaviour of the river in the plain area. All the years with 500 cumec and above values indicate the flood condition in the study reach that plays a very significant role in the formation and dynamics of braided planform. Seasonal discharge variability is another key factor of the dynamics of the Tista River. The images of 1990 and 2010 that have been prepared for the analysis of braided planform dynamics of the Tista River, are the winter season images and show aclear view of the braided structure (Fig. $3 \&$ Fig. 4). But the monsoon season images show a single channel flow and the braided structures are overwhelmed by bank full monsoon discharge. So, the seasonality alone has a significant role in the braided planform dynamics of the river. Fig. 7 shows a rating curve or stage-discharge $(\mathrm{H}-\mathrm{Q})$ relationship. The figure indicates high fluctuations among all average daily discharges with small changes of the stages probably because of the channel's wideness.

A similar type of mechanism and condition has been found in the case of the Kosi River. The river is also in the braided form in the North Bihar Plain and has formed a megafan (Kosi Megafan). The river is highly dynamic and moved to the west. The construction of barrage, embankments and the event of flash floods etc. play the lead role in the channel dynamics and the formation of the megafan (Sinha, 2009; Chakraborty, et al., 2010). Another example of braided channel dynamics is the behaviour of the River Ganga in 
the upstream and downstream of Farakka Barrage (Rudra, 2010; Sinha and Ghosh, 2012; Gupta, et al., 2013; Pal, 2015).

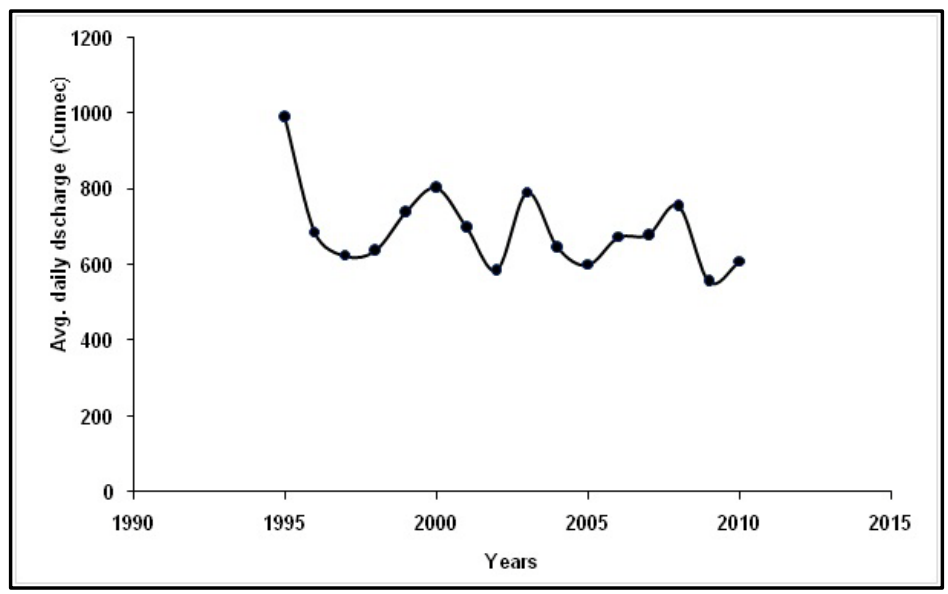

Fig. 6: Temporal variability of total discharge at Gajoldoba Barrage in the period of 19952010. The high values are the indicator of annual flood events.

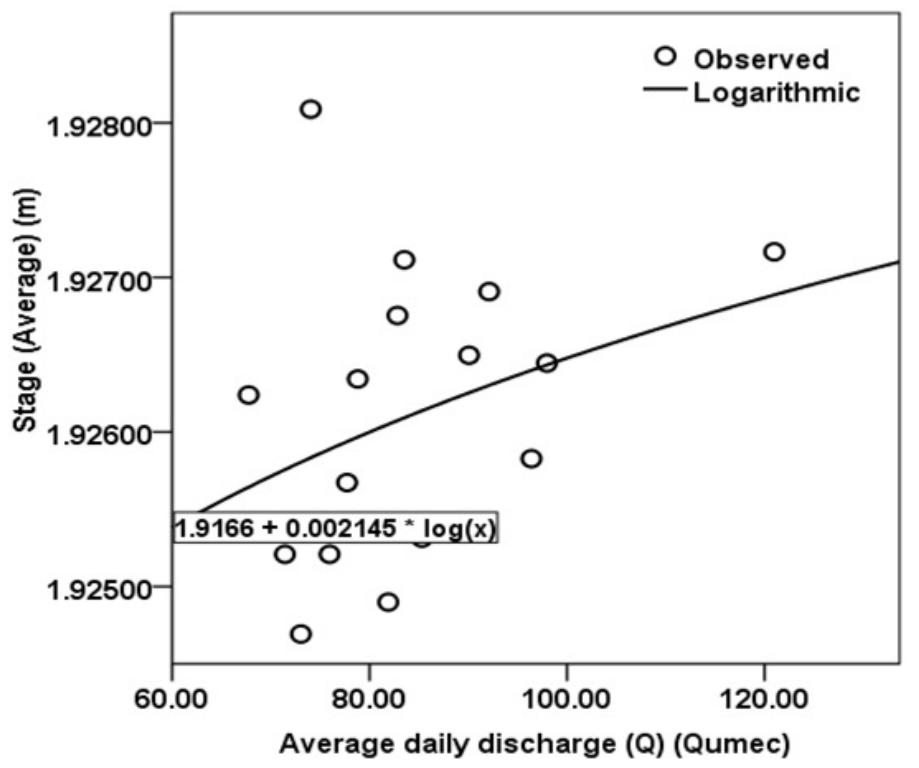

Fig. 7: A rating curve or stage-discharge relationship with the help of stage and daily average discharge data (1995-2010) of Gajoldoba barrage.

The Tista Basin is highly sensitive in terms of its sediment yield rate, fragile geology, earthquakes and flashes floods etc. (Agarwal and Narain, 1991). Historical records of earthquake indicate that the basin is tectonically active and but neo-tectonic imprints are not very prominent in the basin. Moreover, channel morphology of the river does not show any significant imprint that caused by neo-tectonic events and the channel floor is established on the sedimentary deposit of the Tista Megafan constituent (Fig. 2). Some stable ground points exist in the study reach viz. the barrage, immediately downstream of the barrage, near Jalpaiguri and the west bank line in the upstream that help to shape the channel planform into the present form. Further, flash flood events are very common in the Tista Basin and have an immense impact on the channel planform over decades though the river flow is deceased at the confluence because of detention of flow (barrage construction). The flow remains relatively very high only during the monsoon season. Pre and post monsoon cloudburst in the 
Sikkim and Darjeeling play very significant role in the occurrence of floods that enforce the channel planform to be modified (Agarwal and Narain, 1991). Some of the major floods occurred in 1968, 1973, 1975, 1993, 1996, 2000, 2003 and 2015 that have a crucial role in the channel dynamics.

\section{Conclusion}

Channel braiding is a common form where a river enters into the plain from the hilly environment and some features like alluvial fans, alluvial cones and channel bifurcations etc. are developed as the output of the process. The Tista River is standing with its bifurcated channel floor and has formed a large fan to the west of the river. The longitudinal extent of the study is about $50 \mathrm{~km}$ with a gentle slope which is controlled by natural factors as well as engineering constructions (barrage, bridge and embankments etc.). The study is mainly focused on the last 20 years (1990-2010) behaviour of the channel and it has been identified that the construction of Gajoldoba Barrage as well continual event of flash floods have an immense role in the recent modification of the Tista River. The river in the downstream (Gajoldoba to Jalpaiguri) is migrated to the west throughout the course. It is one of the finest examples of the impact of the barrage of the downstream channel modification. Historical records and the recent modification of the river indicate that the river basin is highly dynamic. Problems related to the river basin environment have come into existing. Many illegal settlements have been established on the channel bars in the last few decades that have made the river more vulnerable. Because the bars are very unstable and almost every year the bars are completely inundated due to huge discharge release from the barrage during cloudburst and heavy monsoon rainfall that make a disaster and compel people to be marooned and disaster prone. It is an urgent issue for river researcher to find out some ways to conciliate the disasters and save the river basin environment.

\section{Appendix :}

Braid - channel ratio (bfd)

$=$

Sum of the mid - channel length of all segments in a reach

Mid - channel length of the primary channel in the same reach

$$
\text { Sinuosity Index }(\mathrm{P})=\frac{\text { Length of primary channel in a reach }}{\text { Straight length of the channel in the same reach }}
$$

Rating curve or stage-discharge relationship (Subramanya, 2013),

Or, $Y=B X+b$

$$
\begin{gathered}
Q=\operatorname{Cr}(G-a)^{B} \\
\log Q=B \log (G-a)+\log C r \\
B=\frac{N\left(\sum X Y\right)-\left(\sum X\right)\left(\sum Y\right)}{N\left(\sum X^{2}\right)-\left(\sum X^{2}\right)} \\
b=\frac{\sum Y-B\left(\sum X\right)}{N}
\end{gathered}
$$

Where,

$Q=$ stream discharge $(X)$

$G=$ gauge height (stage) $(Y)$

$a=$ gauge height corresponding to zero discharge

$B$ and $\mathrm{Cr}(\mathrm{b}=\log \mathrm{Cr})=$ rating curve constant 
Acknowledgements:The authors are highly thankful to the Centre for the Study of Regional Development (CSRD), School of Social Science (SSS), Jawaharlal Nehru University (JNU) for providing the hydrological data of the Tista River.

\section{References}

Agarwal, A., and Narain, S. (1991)Floods,Flood Plain and Environmental Myths (State of India's Environment: A Citizens' Report, 3). New Delhi, Centre for Science and Environment. pp. 3239.http://csestore.cse.org.in/usd/soe3.html.

Begin, Z. (1981) The relationship between flow shear stress and stream pattern. J. Hydrology, v. 52, pp.307-319. Carson, M. (1984) The meandering-braided river threshold: a reappraisal. J. Hydrology, v. 73, pp. 315-334.

Chakraborty, T. and Ghosh, P. (2010) The geomorphology and sedimentology of the Tista megafan, Darjeeling Himalaya. Geomorphology, v.115, pp.252-266.

Chakraborty, T., Kar, R., Ghosh, P. and Basu, S. (2010) Kosi megafan: Historical records, geomorphology and the recent avulsion of the Kosi River. Quaternary International, v. 227(2), pp. 143-160.

Eaton, B. C., Robert, M. G. and Davidson, S. (2010) Channel patterns: Braided, anabranching and single-thread. Geomorphology, v.120, pp. 353-364.

Friend, P. F. and Sinha, R. (1993) Braiding and meandering parameters. Geological Society Special Publication, v. 75, pp. 105-111.

Ghosh, K. (2013) Changing pattern of channel planform after Gazaldoba barrage construction, Teesta River,West Bengal.Unpublished M.Phil. dissertation, CSRD, JNU. New Delhi

Gupta, N., Atkinson, P. A. and Carling, P. A. (2013) Decadal length changes in the fluvial planform of the River Ganga: braiding a mega-river to life with Landsat archives. Remote Sensing Letters, v. 4, pp.1-9.

Henderson, F. (1966)Open Channel Flow. New York: Macmillan.pp. 235-250, 356-391.

Lane, E. (1957)A study of the shape channels formed by natural streams flowing in erodible material. Omaha,NB: U.S. Army Eng. Division. pp. 11-98.

Leopold, L. and Wolman, M. (1957)River channels patterns: Braided, Meandering and straight. Washington, DC: U.S. Geological Survey.pp. 39-72.

https://www.uvm.edu/ wbowden/Teaching/Stream_Geomorph_Assess/Resources/Private/Documents/ 1957_leopold_wolman_channel_patterns.pdf.

Mukhopadhyay, S. (1982) The Tista Basin. New Delhi: K P Bagchi and Company.pp. 3-28.

Pal, R. (2015) Fluvial planform dynamics and adjoining floodplain morphology: A Study from the middle-lower part of the River Ganga, India. Unpublished M.Phil. dissertation, CSRD, JNU,New Delhi.

Rudra, K. (2010)Banglar Nadikatha (Bengali). Kolkata: Sahitya Sanshad. pp. 74-76.

Rudra, K. (2010). Dynamics of the Ganga in West Bengal, India (1764-2007): Implications for science policy interaction. Quaternary International, v. 227, pp.161-169.

Sefe, F. T. (1996) A study of the stage-discharge relationship of the Okavaiigo River at Mohembo, Botswana. Hydrological Sciences Journal, v. 41(1), pp. 97-116.

Singh, R. (1971)India: A Regional Geography. Varanasi: National Geographical Society of India.pp. 256-259.

Sinha, R. (2009) The Great Avulsion of Kosi on 18 August 2009. Current Science, v. 97, pp. 429-432.

Sinha, R. and Friend, P. F. (1994) River systems and their sediment flux, Indo-Gangetic plains, Northern Bihar, India. Sedimentology, v. 41, pp. 825-845.

Sinha, R. and Ghosh, S. (2012) Understanding dynamics of large rivers aided by satellite remote sensing: a case study from Lower Ganga plains, India. Geocarto International, v. 27(3),pp. 207-219.

Subramanya, K. (2013)Engineering Hydrology. McGraw Hill Education (India) Private Limited,New Delhi, pp. 145-150.

Wadia, D. N. (1975). Geology of India (4th ed.). Tata McGraw-Hill,New Delhi, pp. 390-412.

(Received: 02.02.2016; Accepted: 13.04.2016) 